This article appeared in a journal published by Elsevier. The attached copy is furnished to the author for internal non-commercial research and education use, including for instruction at the authors institution and sharing with colleagues.

Other uses, including reproduction and distribution, or selling or licensing copies, or posting to personal, institutional or third party websites are prohibited.

In most cases authors are permitted to post their version of the article (e.g. in Word or Tex form) to their personal website or institutional repository. Authors requiring further information regarding Elsevier's archiving and manuscript policies are encouraged to visit:

http://www.elsevier.com/copyright 


\title{
What is the identity of a sports spectator?
}

\author{
L. Gregory Appelbaum ${ }^{\mathrm{a}, \mathrm{b}, *}$, Matthew S. Cain ${ }^{\mathrm{a}, \mathrm{c}}$, Elise F. Darling ${ }^{\mathrm{a}, \mathrm{c}}$, Steven J. Stanton ${ }^{\mathrm{a}, \mathrm{c}}$ \\ Mai Thi Nguyen ${ }^{\mathrm{d}}$, Stephen R. Mitroff ${ }^{\mathrm{a}, \mathrm{c}}$ \\ ${ }^{a}$ Center for Cognitive Neuroscience, Duke University, United States \\ ${ }^{\mathrm{b}}$ Department of Psychiatry, Duke University, United States \\ ${ }^{\mathrm{c}}$ Department of Psychology \& Neuroscience, Duke University, United States \\ ${ }^{\mathrm{d}}$ Department of City and Regional Planning, University of North Carolina, Chapel Hill, United States
}

\section{A R T I C L E I N F O}

\section{Article history:}

Received 13 August 2011

Received in revised form 25 October 2011

Accepted 30 October 2011

Available online 23 November 2011

\section{Keywords:}

Sports spectators

Hormones

Personality scales

ADHD

Autism

Video game playing

Exercise

\begin{abstract}
A B S T R A C T
Despite the prominence of sports in contemporary society, little is known about the identity and personality traits of sports spectators. With a sample of 293 individuals, we examine four broad categories of factors that may explain variability in the reported amount of time spent watching sports. Using individual difference regression techniques, we explore the relationship between sports spectating and physiological measures (e.g., testosterone and cortisol), clinical self-report scales (ADHD and autism), personality traits (e.g., NEO "Big Five"), and pastime activities (e.g., video game playing). Our results indicate that individuals who report higher levels of sports spectating tend to have higher levels of extraversion, and in particular excitement seeking and gregariousness. These individuals also engage more in complementary pastime activities, including participating in sports and exercise activities, watching $\mathrm{TV} /$ movies, and playing video games. Notably, no differences were observed in the clinical self-report scales, indicating no differences in reported symptoms of ADHD or autism for spectators and non-spectators. Likewise, no relationship was seen between baseline concentrations of testosterone or cortisol and sports spectating in our sample. These results provide an assessment of the descriptive personality dimensions of frequent sports spectators and provide a basic taxonomy of how these traits are expressed across the population.
\end{abstract}

(c) 2011 Elsevier Ltd. All rights reserved.

\section{Introduction}

Watching sporting events has a long tradition dating back at least to the first Olympics in 776 BC. In contemporary society, sport spectating serves as a pervasive leisure activity with hundreds of millions of fans worldwide. In 2010 alone, there were over $40,500 \mathrm{~h}$ of live sporting events on broadcast and cable TV (Neilsen Company, 2011) and a single sporting event in 2011, the National Football League's Super Bowl, garnered 111 million viewers making it the most watched telecast of all time (Seidman, 2011). Given the prominence of sport spectating in our society there is surprisingly little research on what factors predict the amount of time individuals spend watching sports. It is therefore important to understand the behaviors and personality traits of sports spectators in order to better identify what individual difference factors are associated with this important pastime activity. In the present study, we take an exploratory approach to identify individual difference factors in a wide variety of domains from personality to

\footnotetext{
* Corresponding author. Address: Center for Cognitive Neuroscience, Duke University, Box 90999, Durham, NC 27708, United States. Tel.: +1 919684 1715; fax: +1 9196810815

E-mail address: greg@duke.edu (L. Gregory Appelbaum).
}

physiology that predict individuals' time investment in sports spectating.

The goal of the current study is to expand upon previous studies to explore a variety of factors that may or may not relate to sports watching behavior. While here we focus on sports "spectating", previous research has broadly distinguished between two related concepts: the sports fan and the sports spectator (Giulianotti, 2002; Jacobson, 2003; Sloan, 1989). Fans and spectators have many overlapping qualities, but a key distinction is that a fan is typically associated with an emotional link to a sport or team, while a spectator is a more neutral descriptor of an individual who consumes sports (Wann \& Dolan, 2001). Since the two concepts are intertwined, we review the literature on both fans and spectators, but the focus of our study is specifically on the characteristics of a sports spectator.

Specialized scales have been developed to assess what psychological factors motivate individuals to watch sports (e.g., entertainment, escapism, aesthetics, or group affiliation) and the specific means by which spectators engage (e.g., live, TV and web) with sporting events. These scales have revealed details about sports spectators' views towards specific sports (McDonald, Milne, \& Hong, 2002; Wann, 1995) and teams (Giulianotti, 2002), about basic demographic details (e.g., age, race, gender and income) of sport 
spectators and fans (Funk, Ridinger, \& Moorman, 2004; Sargent, Zillmann, \& Weaver, 1998; Wann, 1995) and about patterns of sport consumption (e.g., sporting events attendance) associated with different levels of motivation (Shank \& Beasley, 1998). For example, it has been shown in multiple samples that sports spectators are more likely to be young and male (Gantz \& Wenner, 1991; Sargent et al., 1998; Wann, 1995).

Research into sports fans has revealed links between fan behavior and both social constructs and physiological factors. For example, highly invested fans are more likely to seek enhanced social interactions and a better sense of community through sports (Jacobson, 2003; McDonald et al., 2002). Likewise, male fans whose teams are victorious tend to experience increases in testosterone, whereas male fans whose teams lose have decreases in testosterone (Bernhardt, Dabbs, Fielden, \& Lutter, 1998). This physiological arousal of testosterone nicely depicts the emotional component of the sports fan definition, as manifested in the interaction of psychology and physiology. Similarly, links have also been demonstrated between sports fans and violence, generally finding that more invested fans engages in more violent and aggressive behavior (Branscombe \& Wann, 1992; Wann, 1993). Previous research has also addressed how fans internalize team success (Wann \& Dolan, 2001) and how assertiveness and self-esteem are manifested in sports fans (Toros, 2011).

The above work has started the process of delineating the nature of a sports spectator, and through this process specific characteristics and psychological typologies of a spectator have begun to emerge. However, key questions remain. To better understand the identity of a sport spectator, it would be helpful to know in what other ways spectators differ, and do not differ, from non-spectators. To address this question our strategy in the current study was to gather broad demographic, physiological, clinical, psychological, and pastime-preference information about a large group of individuals to see what factors most reliably predicted sport spectating habits. We included a variety of measures, including steroid hormones, the "Big Five" personality traits, and the Autism Spectrum Quotient. The breadth of these measures allows the current study to contribute to the sports spectator research by expanding the scope of the assessment measures. Such 'individual difference' approaches have a long history in social psychology research and have revealed how individual traits or attributes can predict certain behaviors (Bauer, 2011; Cohen, Cohen, West, \& Aiken, 2003; Revelle, Condon, \& Wilt, 2010). Our individual differences approach here revealed factors that do and do not predict sports spectating, which further inform the study of the identity of a contemporary sports spectator and thus provide a broad taxonomy of this population.

\section{Methods}

\subsection{Participants}

The current study involved 321 participants who undertook a series of assessments across multiple testing sessions as part of a larger research endeavor conducted in the Duke University Visual Cognition Lab. The participants received course credit or $\$ 10$ per hour in compensation. All participants were 18 or older and voluntarily participated under an experimental protocol approved by Duke University's institutional review board and conforming to the Code of Ethics of the World Medical Association.

\subsection{Measures}

The participants completed self-report assessments that measured characteristics across a broad scope of demographic, physio- logical, clinical, psychological, and pastime-preference information. As part of a pastimes questionnaire that was generated within the lab, the participants were asked, "On average, how many hours a week do you spend watching sports?" They reported their answer on a 7-point scale with ordinal responses of: "less than 10 min", "10 min to $1 \mathrm{~h}$ ", " $1-3 \mathrm{~h}$ ", “3-5 h", "5-10 h", "10-20 h", and "greater than $20 \mathrm{~h}$ " per week. This question serves as the primary dependent measure for the current study. In order to establish what factors most reliably predicted sport spectating habits, key assessment variables of interest were selected for regression analysis. These variables are broken down into four categorical groupings of physiological, clinical, personality, and pastime variables, and are described in detail in Table 1.

\subsection{Procedure}

Prior to statistical assessment, several pre-processing steps were applied to the full set of assessment measures. From a larger sample of 321 participants, 28 participants were excluded due to incomplete assessments (missing $>10$ of the 65 variables) leaving 293 participants, aged 18 through 58 (179 female, mean age 21.312 years, $\mathrm{SD}=5.302) .{ }^{1}$ Bivariate correlations revealed that all variables had joint correlations less than 0.7 and, therefore, no models were in violation of multicollinearity.

The general analysis strategy was to build nested regression models that contained a priori defined sets of theoreticallygrouped assessment data so that we could determine which factors best-predicted sport watching. We began by building a base model composed of the two basic demographic variables of gender and age since these two variables have consistently been related to sport spectating (Gantz \& Wenner, 1991; Sargent et al., 1998; Wann, 1995). The role of the base model was to provide a basis for determining what additional factors significantly accounted for variance in sport watching above and beyond gender and age.

Beyond the base model, we constructed four 'categorical' regression models. We compared the change in $R^{2}$ value between the base model and other models to see if the addition of specific, targeted sets of measures would result in an improved prediction of the primary dependent variable. These models were followed by a combined, multivariate model in which the significant predictors from each of the categorical models were entered. By jointly combining the significant variables from each individual model into a final, combined model, we were able to determine the relative contributions of the significant variables.

\section{Results}

\subsection{Base model}

The 2-parameter base model of gender and age significantly accounted for variability in sport watching $\left(R^{2}=0.121, F(2,290)=\right.$ $19.876, p<0.001)$ and both factors were significant predictors of the dependent variable (gender: $\beta=-0.914, \quad p<0.001$; age: $\beta=-0.038, p=0.008$ ). These results confirmed our $a$ priori predictions that younger males tend to spend more time engaged in sports spectating. These variables were used as base predictors for all subsequent regression models (see Table 2 for means, standard deviations, beta coefficients, and significance values for all categorical variables).

\footnotetext{
${ }^{1}$ Due to the relatively large skew in the ages of our participants, we re-did the analysis with a subset of 267 participants (18-26 years, mean age 20.020 years, $\mathrm{SD}=2.055)$. This more homogenous data set yielded the same results except that the AQ "social skills" subscale $(\beta=-0.091, p=0.094)$ and the NEO "gregariousness" subscale $(\beta=0.037, p=0.091)$ trended, but did not reach significance.
} 
Table 1

Descriptions of variables and their categorical arrangement.

Physiological variables

Steroid hormones: Saliva was collected for the measurement of baseline testosterone and cortisol. Saliva samples were processed and radioimmuno assayed (see for details: Schultheiss \& Stanton, 2009; Stanton, Beehner, Saini, Kuhn, \& LaBar, 2009; Stanton, LaBar, Saini, Kuhn, \& Beehner, 2010). Analytical sensitivity ( $B_{0}$ - 3 SD) was $2.93 \mathrm{pg} / \mathrm{mL}$ for testosterone and $0.04 \mathrm{ng} / \mathrm{mL}$ for cortisol. All saliva samples were counted in duplicate and had a mean intra-assay coefficients of variation of $8.0 \%$ for testosterone and $4.8 \%$ for cortisol. Due to skew, raw cortisol values $(M=3.144, \mathrm{SD}=2.500)$ were log-transformed. Raw testosterone values were: Men $M=81.652 \mathrm{pg} / \mathrm{mL}, \mathrm{SD}=29.903$; Women $M=15.742 \mathrm{pg} / \mathrm{mL}, \mathrm{SD}=7.746$ - these values are consistent with past studies (Stanton et al., 2009). Testosterone values were $z$-score transformed within each gender so that we could collapse across gender in our analyses.

2D:4D digit ratio: This measures the ratio of the lengths of the 2 nd (index) and 4th (ring) fingers. This ratio, derived from photo scans of each participant's dominant hand and calculated using the AutoMetric software program (Kemper \& Schwerdtfeger, 2009), is a proxy of prenatal androgen exposure and has been shown to correlate with psychological disorders (e.g., autism, Manning, Baron-Cohen, Wheelwright, \& Sanders, 2001; e.g., ADHD Stevenson et al., 2007) and cognitive abilities (van Anders \& Hampson, 2005).

Clinical scale variables

Autism Spectrum Quotient (AQ): Autism is a complex disorder with a spectrum of severity and symptoms. The AQ (Baron-Cohen, Wheelwright, Skinner, Martin, \& Clubley, 2001) offers five sub-scales: social skill, attention switching, attention to detail, communication, and imagination.

Jasper/Goldberg adult ADD/ADHD questionnaire: ADHD is a multifaceted condition with symptoms of impulsivity, hyperactivity, and inattention. This self-report questionnaire designed for adults uses 24 questions to determine a respondent's risk of having adult ADHD (Jasper \& Goldberg, 1993).

Personality scale variables

NEO personality inventory (NEO-PI-R): The NEO-PI-R is a standard personality assessment that measures the "Big Five" personality traits (neuroticism, extraversion, openness, agreeableness, and conscientiousness), with six facets of each trait (Costa \& McCrae, 1992).

Barratt Impulsivity Scale (BIS-11): The BIS-11 (Patton, Stanford, \& Barratt, 1995) is a 30-item questionnaire that assesses three subscales of impulsiveness: attentional, motor, and non-planning.

Pastime activity variables

Self-report of pastime involvement: This questionnaire asks participants how many hours a week they spend on the following activities: reading, sudoku puzzles, listening to music, exercising/playing sports, watching television and movies, experiencing the outdoors, volunteer work, playing video games, and watching sports. Participants report their answer for each activity on a 7-point scale with ordinal responses of: "less than $10 \mathrm{~min}$ ", "10 min to 1 h", 1-3 h", "3-5 h", "5-10 h", "10$20 \mathrm{~h}$ ", and "greater than $20 \mathrm{~h}$ " per week.

\subsection{Physiological model}

Testosterone and cortisol hormone levels, and 2D:4D digit ratios were collected for 217 of the total 293 participants. Initial tests for equality of means (independent samples $t$-tests) revealed that those participants who did, and did not, have these physiological

\section{Table 2}

Group means, standard deviations, beta coefficients, and significance values for each variable as computed separately in the base model and the four categorical models (excluding subscales)

\begin{tabular}{lllll}
\hline Variables & Mean & Std. Dev. & $\beta$ & $p$-Value \\
\hline $\begin{array}{l}\text { Base variables } \\
\text { Gender (61\% female) }\end{array}$ & & & & \\
Age & 21.312 & 5.302 & -0.380 & $0.001^{* *}$ \\
Physiological variables & & & & \\
Cortisol (log) & 0.911 & 0.716 & 0.123 & 0.366 \\
Testosterone (z-score) & 0.039 & 1.000 & 0.015 & 0.874 \\
Digit ratio & 0.970 & 0.034 & 1.346 & 0.619 \\
Clinical variables & & & & \\
Autism-total & 16.744 & 5.880 & 0.005 & 0.263 \\
ADHD & 34.655 & 17.662 & -0.029 & $0.034^{*}$ \\
Personality variables & & & & \\
Impulsivity-total & 60.879 & 9.509 & 0.013 & 0.138 \\
Neuroticism-total & 102.147 & 19.668 & -0.001 & 0.883 \\
Extraversion-total & 109.044 & 19.628 & 0.016 & $0.001^{* *}$ \\
Openness-total & 108.369 & 16.436 & -0.002 & 0.732 \\
Agreeableness-total & 94.840 & 22.881 & 0.001 & 0.812 \\
Consciousness-total & 105.464 & 22.727 & -0.001 & 0.750 \\
Pastime variables & & & & \\
Watching sports (DV) & 2.587 & 1.381 & $\mathrm{~N} / \mathrm{A}$ & $\mathrm{N} / \mathrm{A}$ \\
Reading & 4.027 & 1.494 & -0.010 & 0.851 \\
Playing sudoku & 1.491 & 0.898 & 0.092 & 0.270 \\
Playing musical instruments & 4.509 & 1.529 & 0.094 & 0.090 \\
Playing sports/exercising & 3.883 & 1.490 & 0.178 & $0.001^{* *}$ \\
Watching TV/movies & 3.705 & 1.351 & 0.187 & $0.001^{* *}$ \\
Spending time outdoors & 2.297 & 1.334 & 0.062 & 0.281 \\
Volunteer work & 2.089 & 1.301 & 0.018 & 0.757 \\
Video game playing & 2.069 & 1.498 & 0.151 & $0.011^{* *}$ \\
\hline
\end{tabular}

$<.05$ Significance

$<.01$ Significance. measures did not differ systematically on any of the other dependent or independent variables. Subsequent multivariate regression analyses on the 217 individuals revealed that while the base model significantly predicted sports spectating $[F(2,214)=8.880$, $p<0.001$ ], the addition of the physiological variables did not significantly improve the fit above that of the base model, $\left[R^{2}\right.$ change: $F(3,211)=0.502, p=0.681]$.

\subsection{Clinical scales model}

The Autism Spectrum Quotient (AQ) and Jasper/Goldberg Adult ADD/ADHD Questionnaire were collected on all 293 participants. Regression analyses on all 293 participants revealed that the addition of these clinical variables trended towards a significant improvement in the fit of the model above the base model $\left[R^{2}\right.$ change: $F(2,288)=2.556, p=0.079]$. Of interest, it was observed that within this model the summary measure of the AQ produced a significant negative relationship $(\beta=-0.029, p=0.034)$ with sports spectating. We therefore further probed the relationship with symptoms of autism by rerunning the model with the five subscales of the AQ. This additional, post hoc analysis revealed that the AQ subscale variables produced significant improvement beyond the base model $\left[R^{2}\right.$ change: $\left.F(5,285)=2.754, p=0.019\right]$. This improved fit was driven primarily by a significant negative relationship between sports spectating and the AQ "Social Skills" subscale measure $(\beta=-0.101, p=0.033)$.

\subsection{Personality scales model}

The NEO Personality Inventory (NEO-PI-R) and Barratt Impulsivity Scale (BIS-11) measures were collected on 280 of the 293 participants. Regression analyses on these individuals revealed that the base model significantly predicted sports spectating, $[F(2,277)=16.207, p<0.001]$, and that the addition of the "Big Five" NEO-PI-R traits (see Table 1) and the BIS cumulative score produced a significant improvement in the fit of the model above the base variables [ $R^{2}$ change: $F(6,271)=2.975, p=0.008$ ] . This improved prediction of the personality scales model was driven principally by a significant positive relationship between sports 
watching and the extraversion subscale of the NEO-PI-R $(\beta=0.016$, $p=0.001$ ). To further assess the underlying traits contributing to this relationship, post hoc regression analysis of the six extraversion subscales and two base variables were performed. This analysis revealed positive relationships between sports spectating and both the "excitement seeking" ( $\beta=0.051, p=0.007$ ) and "gregariousness" ( $\beta=0.039, p=0.048)$ subscales. None of the other subscales were significantly associated with sports watching.

\subsection{Pastime activities model}

Seven-point ordinal pastime self-report assessments were collected on 282 out of the 293 participants. Here we assessed the following activities: reading, listening to music, exercising and playing sports, watching television and movies, experiencing the outdoors, sudoku puzzles, volunteering, and playing video games. Regression analyses revealed that the base model significantly predicted sports spectating $(F(2,279)=18.034, p<0.001)$ and that the addition of the pastime variables resulted in a significant improvement in predictive fit above that of the base model $\left(R^{2}\right.$ change: $F(8,271)=6.909, p<0.001)$. This improved prediction of the pastime model was driven principally by a significant positive relationship between sports watching and time spent watching TV and movies $(\beta=0.187, p=0.001)$, time spent exercising and playing sports $(\beta=0.178, p=0.001)$, and time spent playing video games $(\beta=0.151, p=0.011)$.

\subsection{Cumulative model}

To assess the relative contribution of all significant variables identified in the individual categorical models, these significant variables were compared in a single multivariate regression analysis including all of the 288 participants for whom all of these measures had been collected. This 8-parameter model included age, gender, social skills (AQ subscale), gregariousness (NEO-PI-R subscale), excitement seeking (NEO-PI-R subscale), and the pastimes of video game playing, engaging in sports/exercise, and TV/movie watching. This cumulative model resulted in a significant fit

Table 3

Cumulative model variables rank-ordered by their standardized beta coefficients. $\mathrm{AQ}=$ Autism Spectrum subscale. $\mathrm{NEO}=\mathrm{NEO}-\mathrm{PI}-\mathrm{R}$ extraversion subscale. $\mathrm{PT}=$ pastime.

\begin{tabular}{lcc}
\hline Variable & Standardized $\beta$ & $p$-Value \\
\hline Gender & -0.219 & $<0.001$ \\
Age & -0.100 & 0.054 \\
Social skills (AQ) & -0.065 & 0.262 \\
Gregariousness (NEO-PI-R) & 0.116 & 0.044 \\
Excitement seeking (NEO-PI-R) & 0.135 & 0.012 \\
Video Gaming (PT) & 0.187 & 0.002 \\
Exercise (PT) & 0.215 & $<0.001$ \\
TV/movies (PT) & 0.203 & $<0.001$ \\
\hline
\end{tabular}

$\left(R^{2}=0.306, F(8,279)=15.380, p<0.001\right)$. Six of the eight individual coefficients (shown in Table 3 ) reached significance, one, age, approached significance $(p<0.054)$, and one, social skills, failed to reach significance $(p=0.262)$. This suggests that these factors possess robust predictive value in estimating the amount of time individuals spend watching sporting events.

\subsection{Correlation matrix of significant predictor variables}

The primary dependent variable in the current experiment asked participants to report how many hours they spend watching sports. This does not allow for a distinction between watching sports via television compared to other means. Given that we found a positive relationship between watching sports and the variable of "watching TV/movies", it is possible that we have conflated sports spectating with simply watching TV. One-way to assess this potential confound is to compute bivariate correlations between all of the significant variables identified in the regression analyses (see Table 4). As can be seen in the correlation structure of pastime variable "TV/movies" and "watching sports", these two activities have strikingly different patterns of relationships. While they are highly correlated between each other $(r=0.224, p<0.001)$, they are generally different predictors of the other relevant variables. For example, while "sports watching" is highly positively correlated with the NEO-PI-R subscale of excitement seeking $(r=0.260, p<0.001), \mathrm{TV} /$ movies is not at all associated $(r=0.064$, $p=0.1)$.

\section{Discussion}

Our approach revealed several factors that predict the amount of time individuals report watching sports. We evaluated four categories of possible influences and found that certain personality traits and other pastime activities significantly varied with sports spectating. Specifically, we found that individuals who reported increased sports spectating also tended to report higher levels of extraversion, and in particular excitement seeking and gregariousness. These individuals also tended to report spending more time watching TV and movies, being engaged in sports and exercise activities, and playing video games. No effects were observed using clinical measures as predictors (ADHD and Autism Spectrum), nor were effects detected as a function of baseline testosterone and cortisol concentrations.

Group affiliation is a core dimension of many of the existing sports fan scales (Jacobson, 2003; McDonald et al., 2002) suggesting that personality attributes associated with group interactions may predict sports involvement. Our significant relationship between sports watching and the extraversion subscale of the NEOPI-R personality scale supports this prediction. Likewise, previous work has found that factors such as "eustress" (good stress), "escape", and "entertainment" relate to sports watching (Wann,

Table 4

Bivariate Pearson correlations of significant combined model variables.

\begin{tabular}{|c|c|c|c|c|c|c|c|c|}
\hline & Gender & Age & Gregarious-ness & Excitement seeking & Video gaming & Exercise & TV/movies & Watching sports \\
\hline \multicolumn{9}{|l|}{ Gender } \\
\hline Age & -0.053 & & & & & & & \\
\hline Gregarious-ness & 0.078 & -0.074 & & & & & & \\
\hline Excitement seeking & -0.118 & -0.067 & $0.296^{* *}$ & & & & & \\
\hline Video gaming & $-0.504^{* * *}$ & 0.042 & -0.086 & 0.108 & & & & \\
\hline Exercise & -0.068 & $-0.143^{*}$ & 0.055 & 0.100 & -0.064 & & & \\
\hline $\mathrm{TV} /$ movies & 0.051 & 0.073 & -0.027 & 0.064 & 0.104 & 0.028 & & \\
\hline Watching sports & $-0.315^{* *}$ & $-0.130^{*}$ & $0.163^{* *}$ & $0.260^{* *}$ & $0.306^{* *}$ & $0.272^{* *}$ & $0.224^{* *}$ & \\
\hline
\end{tabular}

\footnotetext{
$<.05$ Two-tailed correlation significance.
}

** $<.01$ Two-tailed correlation significance. 
1995; Wann, Schrader, \& Wilson, 1999). The current relationship between sports watching and "excitement seeking" complements these prior results. Previous work has also found that highly involved sports fans watched more sports-related television programming than low-involvement fans, and also exercised and played more sports (Shank \& Beasley, 1998). Our current observation that exercise and playing sports significantly predicted watching sports supports this prior result.

Whereas the above examples demonstrate ways in which the current results confirm and expand previous findings, some of these new findings may be at odds with prior work. For example, we expected to find a relationship between sports watching and both testosterone and cortisol concentrations, yet none were found. There are prior links between sports fans and violence, generally finding that more invested fans participated in more violent and aggressive behavior (Branscombe \& Wann, 1992; McDonald et al., 2002; Wann, 1993). Further, higher concentrations of testosterone relates to aggression and dominance motivation (Stanton \& Schultheiss, 2009), and past studies have shown that sports spectators' vicarious experience of victory and defeat can lead to changes in testosterone levels (Bernhardt et al., 1998). Thus, it is potentially surprising that we found no relationship between sports watching and testosterone concentrations. Along the same vein, previous work has addressed how fans internalize team success (Wann \& Dolan, 2001) and how assertiveness and self-esteem manifest in sports fans (Toros, 2011). Given that cortisol levels have been shown to reflect psychological outcomes following victories or defeats (Stanton \& Schultheiss, 2009), it was unexpected that we did not find a relationship between sports watching and individuals' cortisol concentrations. One possible explanation for this discrepancy is that our current focus is on sports spectators, who may not necessarily be sports fans (e.g., Giulianotti, 2002).

Beyond the above relationships to sports watching, we also demonstrate several links between sports watching and other pastime activities. As watching sports is also a pastime, these links raise intriguing questions about the nature of the relationships. Specifically, a link between two pastime activities can either reveal a competitive relationship where engaging in one activity takes away time from engaging in the other or a symbiotic relationship where engaging in one activity can increase engagement in another. The bivariate correlations in Table 4 suggest that the relationships we found between sports watching and exercising, video game playing, and watching TV/movies are all symbiotic. First, sports spectating and exercising have shared common interests and exercising does not significantly correlate with any other factor from the model. Second, the link between sports spectating and video game playing appears to be symbiotic: since video game playing and watching TV and movies did not correlate, the relationship cannot be solely driven by media consumption. Finally, as discussed above, the observed relationship between watching sports and watching TV and movies appears to reflect a symbiotic relationship since they are not competing for the same resources.

\section{Conclusion}

The present research takes a broad approach to assess the identity of sports spectators across a number of domains and therefore paints a broad picture of how sports and personality interact in contemporary society. Our data replicate prior results (e.g., sports watching is predicted by gender), expand the literature through several observed positive relationships (e.g., sports watching is predicted by greater levels of extraversion), and expand the literature by revealing non-significant relationships (e.g., sports watching is not predicted by testosterone or cortisol levels, symptoms of ADHD, or impulsivity).

\section{Acknowledgements}

For helpful conversation on the methods and analyses in this research we thank Mark Appelbaum and Stephen Adamo. This work was partially supported by the Army Research Office (\#54528LS) and partially through a subcontract with the Institute for Homeland Security Solutions.

\section{References}

Baron-Cohen, S., Wheelwright, S., Skinner, R., Martin, J., \& Clubley, E. (2001). The autism-spectrum quotient (AQ): Evidence from Asperger syndrome/highfunctioning autism, males and females, scientists and mathematicians. Journal of Autism and Developmental Disorders, 31(1), 5-17.

Bauer, D. (2011). Evaluating individual differences in psychological processes. Current Directions in Psychological Science, 20(2), 115-118.

Bernhardt, P. C., Dabbs, J. M., Jr., Fielden, J. A., \& Lutter, C. D. (1998). Testosterone changes during vicarious experiences of winning and losing among fans at sporting events. Physiological Behavior, 65(1), 59-62.

Branscombe, N. R., \& Wann, D. L. (1992). Role of identification with a group, arousal, categorization processes, and self-esteem in sports spectator aggression. Human Relations, 45(10), 1013-1033.

Cohen, J., Cohen, P., West, S. G., \& Aiken, L. S. (2003). Applied multiple regression/ correlation analyses for the behavioral sciences (3rd ed.). Mahwah, NJ: Erlbaum.

Costa, M., \& McCrae, R. R. (1992). Revised NEO personality inventory (NEO-PI-R) and NEO five-factor inventory (NEO-FFI): Professional manual. Odessa, FL: Psychological Assessment Resources.

Funk, D. C., Ridinger, L. L., \& Moorman, A. M. (2004). Exploring origins of involvement: Understanding the relationship between consumer motives and involvement with professional sport teams. Leisure Sciences, 26, 35-61.

Gantz, W., \& Wenner, L. A. (1991). Men, women, and sports: Audience experiences and effects. Journal of Broadcasting and Electronic Media, 35(233-243).

Giulianotti, R. (2002). Supporters, followers, fans, and flaneurs: A taxonomy of spectator identities in football. Journal of Sport E Social Issues, 26(1), 25-46.

Jacobson, B. (2003). The social psychology of the creation of a sports fan identity: A theoretical review of the literature. Athletic insight. The Online Journal of Sports Psychology, 5(2), 1-14.

Kemper, C. J., \& Schwerdtfeger, A. (2009). Comparing indirect methods of digit ratio (2D:4D) measurement [comparative study]. American Journal of Human Biology, 21(2), 188-191.

Manning, J. T., Baron-Cohen, S., Wheelwright, S., \& Sanders, G. (2001). The 2nd to 4th digit ratio and autism. Developmental Medicine and Child Neurology, 43(3) 160-164.

McDonald, M. A., Milne, G. R., \& Hong, J. (2002). Motivational factors for evaluating sports spectator and participant markets. Sports Marketing Quarterly, 11(2), 100.

Neilsen Company, T. (2011). National People Meter, P2+, live + same day viewing.

Patton, J. H., Stanford, M. S., \& Barratt, E. S. (1995). Factor structure of the Barrat impulsiveness scale. [Research support, non-U.S. Gov't]. Journal of Clinica Psychology, 51(6), 768-774.

Revelle, W. Condon, D. \& Wilt, J. (2010). Individual differences and differential psychology: A brief history and prospect. In T. Chamorro-Premuzic, A. Furnham, \& S. von Stumm (Eds.), Handbook of Individual Differences. Chichester, West Sussex, Malden, MA: Wiley-Blackwell.

Sargent, S. L., Zillmann, D., \& Weaver, J. B. III, (1998). The gender gap in the enjoyment of televised sports. Journal of Sport and Social Issues, 22(46).

Schultheiss, O. C., \& Stanton, S. J. (2009). Assessment of salivary hormones. In E. Harmon-Jones \& J. S. Beer (Eds.), Methods in social neuroscience (pp. 17-44). New York, NY: Guilford Press.

Shank, M. D., \& Beasley, F. M. (1998). Fan or fanatic: Refining a measure of sports involvement. Journal of Sport Behavior, 21.

Sloan, L. R. (1989). The motives of sports fans. In J. H. Goldstein (Ed.), Sports, games, and play: Social and psychological viewpoints (2 ed., pp. 175-240). Hillsdale, NJ: Lawrence Erlbaum.

Stanton, S. J., Beehner, J. C. Saini, E. K., Kuhn, C. M., \& LaBar, K. S. (2009). Dominance, politics, and physiology: Voters' testosterone changes on the night of the 2008 United States Presidential election. PLoS ONE, 4(10).

Stanton, S. J., LaBar, K. S., Saini, E. K., Kuhn, C. M., \& Beehner, J. C. (2010). Stressful politics: Voters' cortisol responses to the outcome of the 2008 United States Presidential election. Psychoneuroendocrinology, 35(5), 768-774.

Stanton, S. J., \& Schultheiss, O. C. (2009). The hormonal correlates of implicit power motivation. Journal of Research in Personality, 43(5), 942-949.

Stevenson, J. C., Everson, P. M., Williams, D. C., Hipskind, G., Grimes, M., \& Mahoney E. R. (2007). Attention deficit/hyperactivity disorder (ADHD) symptoms and digit ratios in a college sample. [Clinical trial]. American Journal of Human Biology, 19(1), 41-50.

Toros, T. (2011). Relationship between the level of assertiveness and self-esteem in university sports spectators. World Applied Sciences Journal, 12(5), 726-731.

van Anders, S. M., \& Hampson, E. (2005). Testing the prenatal androgen hypothesis: Measuring digit ratios, sexual orientation, and spatial abilities in adults. Hormones and Behavior, 47(1), 92-98. 
Wann, D. L. (1993). Aggression among highly identified spectators as a function of their need to maintain positive social identity. Journal of Sport and Social Issues, 17(2), 134-143.

Wann, D. L. (1995). Preliminary validation of the sports fan motivation scale. Journal of Sport and Social Issues, 19(377).

Wann, D. L., \& Dolan, T. J. (2001). Attributions of highly identified sports spectators. Journal of Social Psychology, 134(6), 783-792.

Wann, D. L., Schrader, M. P., \& Wilson, A. M. (1999). Sport fan motivation: Questionnaire validation, comparisons by sport, and relationship to athletic motivation. Journal of Sport Behavior, 22(1), 114.

\section{Web references}

Jasper, L., \& Goldberg, I. (1993). Jasper/Goldberg Adult ADD Questionnaire Retrieved October 1, 2009, from http://www.mentalhelp.net/poc/view_doc.php?id= 974\&type=doc\&cn=ADHD.

Seidman, R. (2011). Super Bowl XLV Breaks Viewing Record, Averages 111 Million Viewers Retrieved 2011-02-07, from http://tvbythenumbers.zap2it.com/2011/ 02/07/super-bowl-xlv-poised-to-break-viewing-records-ties-1987-with-highestovernight-ratings-ever/81684/. 